\title{
A COMPARATIVE STUDY OF CLONIDINE AND DEXMEDETOMIDINE AS AN ADJUVANT IN SUPRACLAVICULAR BRACHIAL PLEXUS BLOCK
}

\author{
Pramod Kumar Palai ${ }^{1}$, Dulal Kishun Soren², Prativa Panda ${ }^{3}$,Sraban Kumar Dash ${ }^{4}$
}

${ }_{1}^{1}$ Associate Professor, Department of Anaesthesiology, VSS Institute of Medical Sciences and Research, Burla, Sambalapur, Odisha. ${ }^{2}$ Associate Professor, Department of Anaesthesiology, VSS Institute of Medical Sciences and Research, Burla, Sambalapur, Odisha.

${ }^{3}$ Professor and HOD, Department of Anaesthesiology, PRM Medical College, Baripada, Mayurbhanj, Odisha.

${ }^{4}$ Postgraduate Student, Department of Anaesthesiology, VSS Institute of Medical Sciences and Research, Burla, Sambalapur, Odisha. ABSTRACT

\section{BACKGROUND}

Supraclavicular block provides anaesthesia for upper extremity in the most consistent andf efficient manner of any brachial plexus technique. Adjuvants when added to local anaesthetics enhance the onset and prolongs the duration of block. $\alpha_{2}$ agonists produce analgesia, sympatholysis and sedation, hence considered as effective adjuvant.

The aim of this study is to compare the efficacy and safety of two $\alpha_{2}$ agonists, i.e. clonidine and dexmedetomidine as an adjuvant for brachial plexus block.

\section{MATERIALS AND METHODS}

It was a prospective, randomised and double-blind study. Sixty patients of ASA grades I and II undergoing forearm surgeries were randomly divided into two groups of 30 patients each. Group C patients received Inj. Bupivacaine (0.5\%) $2 \mathrm{mg} / \mathrm{kg}+\mathrm{Inj}$. Lignocaine (2\%) $5 \mathrm{mg} / \mathrm{kg}$ with adrenaline + Inj. Clonidine $1 \mu \mathrm{g} / \mathrm{kg}$. Group D patients received Inj. Bupivacaine (0.5\%) $2 \mathrm{mg} / \mathrm{kg}+\mathrm{Inj}$. Lignocaine (2\%) $5 \mathrm{mg} / \mathrm{kg}$ with adrenaline + Inj. Dexmedetomidine $1 \mu \mathrm{g} / \mathrm{kg}$. Parameters noted were onset, completion and duration of sensory and motor block, duration of analgesia, Ramsay sedation score, vital parameters and complications if any. Results were analysed by student's unpaired ' $\mathrm{t}$ ' test and chi-square test.

\section{RESULTS}

Onset and time for complete sensory and motor block was significantly faster in the dexmedetomidine group when compared to the clonidine group. The total duration of sensory and motor block and duration of analgesia was also significantly longer in Group D. Both the groups had stable haemodynamics. No complications or side effects were observed in both the groups.

\section{CONCLUSION}

Dexmedetomidine can be used as an adjuvant, alternative to clonidine in supraclavicular brachial plexus block with prolongation of both sensory and motor block, and without any haemodynamic instability and systemic side effects.

\section{KEYWORDS}

Supraclavicular Brachial Plexus Block, Clonidine, Dexmedetomidine, Adjuvant.

HOW TO CITE THIS ARTICLE: Palai PK, Soren DK, Panda P, et al. A comparative study of clonidine and dexmedetomidine as an adjuvant in supraclavicular brachial plexus block. J. Evolution Med. Dent. Sci. 2018;7(14):1806-1810, DOI: $10.14260 /$ jemds/2018/407

\section{BACKGROUND}

The supraclavicular brachial plexus block, often considered the 'spinal anaesthesia of the upper extremity' provides excellent anaesthesia of the upper limb with rapid onset. ${ }^{1}$ It provides superior, long-lasting analgesia and avoids potential side effects of a general anaesthesia, i.e. nausea, vomiting, dental trauma, sore throat and intraoperative haemodynamic swings.

Various opioids and non-opioid agents have been studied as adjuvants, which can be added to the local anaesthetics in peripheral nerve block to improve the duration and quality of

'Financial or Other Competing Interest': None.

Submission 29-12-2017, Peer Review 15-01-2018,

Acceptance 21-03-2018, Published 02-04-2018.

Corresponding Author:

Dr. Dulal Kishun Soren

Department of Anaesthesiology,

VSS Institute of Medical Sciences and

Research, Burla, Sambalapur-768017, Odisha

E-mail: dulalsoren@gmail.com

DOI: $10.14260 /$ jemds $/ 2018 / 407$

\section{(c) (i) $(9)$}

analgesia, but without producing any major adverse effects. The $\alpha_{2}$ agonists Clonidine and Dexmedetomidine have shown potentials as an adjuvant along with local anaesthetics.

This current study is designed to test the hypothesis that dexmedetomidine when added as an adjuvant to mixture of $0.5 \%$ bupivacaine and $2 \%$ lignocaine with adrenaline in brachial plexus block enhances the onset, prolongs duration of sensory and motor block and duration of analgesia as compared with clonidine without causing any major haemodynamic instability or any other systemic side effects.

\section{MATERIALS AND METHODS}

A randomised controlled trial was conducted in a tertiary care hospital after approval of the Institutional Ethics Committee. (No.2015/P-I-RP/116) Patients with American Society of Anesthesiologist Grade I or II status, between 14 and 60 years of either gender, posted for upper limb surgery were included in the present study. Patients who refused to give informed consent, obese and short neck patients, patients with coagulopathy, neuropathy or local infection at the site for block, those with a history of allergy to the study 
drug or of drug abuse and an anticipated operative time more than $2 \mathrm{~h}$ were excluded from the study.

\section{Preoperative Preparation}

On the day of pre-anaesthetic evaluation, informed written consent was obtained in their mother tongue. Patients were fasted overnight. Tab. alprazolam $0.5 \mathrm{mg}$ and Tab. ranitidine $150 \mathrm{mg}$ was given orally the night before surgery.

\section{Method of Collection of Data}

Sixty patients were divided randomly into two groups (Group C, $n=30$ and Group D, n= 30) using a computer-generated programme. Assigned random group was enclosed in a sealed envelope to ensure concealment of allocation sequence. The anaesthesiologist who was not involved in the study, opened the envelope in operation theatre and prepared the drug accordingly. Observations were done by the anaesthesiologist who was blinded to the drug.

\section{Group C}

$(n=30)$ Patients received Inj. (0.5\%) Bupivacaine $2 \mathrm{mg} / \mathrm{kg}$ and Inj. (2\%) lignocaine with adrenaline $5 \mathrm{mg} / \mathrm{kg}$ plus Inj. Clonidine $1 \mu \mathrm{g} / \mathrm{kg}$.

\section{Group D}

( $\mathrm{n}=30$ ) Patients received Inj. (0.5\%) Bupivacaine $2 \mathrm{mg} / \mathrm{kg}$ and Inj. (2\%) lignocaine with adrenaline $5 \mathrm{mg} / \mathrm{kg}$ plus Inj. Dexmedetomidine $1 \mu \mathrm{g} / \mathrm{kg}$.

All drug solutions were prepared by an anaesthesiologist not involved in administration of anaesthesia, patient care and data collection.

Intravenous access was secured with 18-G cannula on the contralateral arm. Patients were monitored for Heart rate, $\mathrm{SpO}_{2}$, non-invasive blood pressure and 3 lead ECG. All patients received supraclavicular brachial plexus block by an experienced anaesthesiologist who was blinded to the grouping.

\section{Efficacy Assessment}

The Effects of Anaesthetics on the following Parameters were observed-

1. Sensory block was evaluated by Hollmen scale and findings were recorded at an interval of every 2 mins from time-0 till complete sensory block is achieved i.e. Hollmen Score $=4$.

\section{Hollmen Scale}

- Score $1=$ Normal sensation to pinprick.

- $\quad$ Score 2= Pinprick felt as sharp pointed, but weaker compared with same area in the other upper limb.

- $\quad$ Score 3= Pinprick recognised as touch with blunt object.

- $\quad$ Score $4=$ No perception of pinprick.

a. Onset Time of Sensory Block was taken as the time interval in minutes from time- 0 till sensory block starts appearing i.e. Hollmen score $=2$.

b. Time for Complete Sensory Block was taken as the duration of time in minutes from time- 0 till complete sensory block is achieved, i.e. Hollmen Score $=4$. Thereafter, effect of block was tested every 30 minutes till 2 hours after end of surgery. c. Total Duration of Sensory Block was taken as the duration of time in minutes from the TCSB till the time when patient came back to Hollmen score- 1 .

2. Motor block was evaluated by using Bromage Scale (BS) for upper extremity and findings were recorded at an interval of every 2 mins from time- 0 till complete loss of motor power is achieved i.e. BS Score $=3$.

\section{Bromage Scale for Upper Extremity}

- 0: Able to raise the extended arm to $90^{\circ}$ for full 2 seconds.

- 1: Able to flex the elbow and move the fingers, but unable to raise the extended arm.

- 2: Unable to flex the elbow, but able to move the fingers.

- 3: Unable to move the arm, elbow and fingers.

a. Onset Time of Motor Block was taken as the time interval in minutes from time-0 till motor block starts appearing i.e. BS score $\geq 2$.

b. Time for Complete Motor Block was taken as the duration of time in minutes from time-0 till complete motor block is achieved, i.e. BS score $=3$. Thereafter, effect of block was tested every 30 minutes till 2 hours after end of surgery.

c. Total Duration of Motor Block was taken as the duration of time in minutes from the TCMB till the time when BS score $<3$ in the postoperative period.

3. Level of sedation was assessed at an interval of every 10 mins from Time- 0 till the end of surgery using Ramsay sedation score.

\section{Ramsay Sedation Score}

1. Patient anxious/ agitated/ both.

2. Patient co-operative, oriented and tranquil.

3. Patient responds to commands only.

4. A brisk response to light glabellar tap.

5. A sluggish response to light glabellar tap.

6. No response.

4. The duration of analgesia was the time when the patients received the first dose of analgesic when visual analogue scale was 4

\section{Visual Analogue Scale (VAS)}

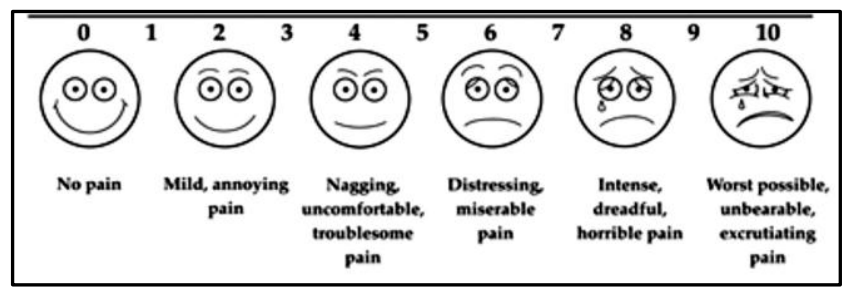

5. Duration of sensory and motor block was assessed every 30 minutes for first 2 hours, every 60 minutes for next 4 hours and then at $9,12,18$ and 24 hours.

6. Complications like inadequacy of block, any reaction at injection site like haematoma, persistent bradycardia, persistent hypotension, over sedation (sedation score $>4$ ), any respiratory distress, fall in respiratory rate to 
$<10$ per min, fall in SpO2 to $<90 \%$, any significant ECG changes and Horner's syndrome were noted.

The above assessments were carried out by the principal investigator who was blinded to the drugs administered.

Sample size calculation was based on an initial study done by Kavitha Jinjil et al (International Journal of Health Care and Biomedical Research, volume: 3, issue: 3, April, 2015) with duration of analgesia as the primary end point of the study. With $\alpha$ error of 0.05 and power of the study (1- $\beta$ ) at $80 \%$, to detect a minimum of 50 mins difference in duration of analgesia between the two groups, the sample size was calculated to be approximately 27 in each group. We included thirty patients in each group to compensate for possible dropouts. The patients who were part of the pilot study were not included in the study. Data was analysed using IBM-SPSS software (SPSS Statistics for Windows, Version 17.0, Chicago: SPSS Inc.). The patients' data and characteristics, the time of onset and duration of the block were categorised and analysed appropriately using student's unpaired t-test and Chi-square test. AP $<0.05$ was considered as statistically significant and a $\mathrm{p}<0.001$ as statistically highly significant.

\section{RESULTS}

There was no significant difference in the patient's characteristics like age, sex, weight and ASA physical status, (Table 1).

The haemodynamic parameters like heart rate, systolic and diastolic blood pressure and oxygen saturation in both the groups were comparable without any statistical significance. The sedation score were also comparable in both the groups without any statistical significance.

\begin{tabular}{|c|c|c|c|}
\hline & Group C (n=30) & Group D (n=30) & P value \\
\hline $\begin{array}{c}\text { Age in Years } \\
(\text { Mean } \pm \text { SD) }\end{array}$ & $36.13 \pm 16.14$ & $38.63 \pm 15.13$ & 0.538 \\
\hline Sex (M: F) & $18: 12$ & $20: 10$ & 0.592 \\
\hline $\begin{array}{c}\text { Weight in kg } \\
\text { (Mean } \pm \text { SD) }\end{array}$ & $59.6 \pm 8.85$ & $60.67 \pm 7.15$ & 0.609 \\
\hline ASA (I: II) & $20: 10$ & $18: 12$ & 0.592 \\
\hline \multicolumn{4}{|c|}{ Table 1. Demographic Variables } \\
\hline
\end{tabular}

\begin{tabular}{|c|c|c|c|}
\hline & $\begin{array}{c}\text { Group C } \\
\text { (Mean } \pm \text { SD) }\end{array}$ & $\begin{array}{c}\text { Group D } \\
\text { (Mean } \pm \text { SD) }\end{array}$ & p value \\
value
\end{tabular}

The statistical analysis of the data in Table 2 by student's unpaired ' $\mathrm{t}$ ' test showed onset time of sensory and motor block, time of complete sensory and motor block, total duration of sensory and motor block and duration of analgesia in Group D was very highly significant in comparison to Group $\mathrm{C}$ with $\mathrm{p}$ value $<0.001$.

\section{DISCUSSION}

The $\alpha 2$ adrenoceptor agonists have been used either alone or in conjunction with local anaesthetics to prolong the duration of analgesia and to improve the quality of the block. ${ }^{2-3}$ In our study, we have compared clonidine and dexmedetomidine as an adjuvant to local anaesthetics in supraclavicular brachial plexus block.

Clonidine has been used in doses between 0.5 to 1.5 $\mu \mathrm{g} / \mathrm{kg}$ in brachial block (Elliott et al, ${ }^{2}$ Singelyn et al ${ }^{3}$ ). In our study we chose dose of $1 \mu \mathrm{g} / \mathrm{kg}$, as no added benefits were found with doses exceeding $1.5 \mu \mathrm{g} / \mathrm{kg}$. Clonidine increases duration of sensory and motor block of lignocaine by inhibition of evoked potential in C-fibre. We used same dose for dexmedetomidine as clonidine, i.e. $1 \mu \mathrm{g} / \mathrm{kg}$ so that both drugs can be compared.
In the present study combination of Lignocaine and Bupivacaine was used for early onset, prolong duration of block and lower the dose of individual drug, thereby reducing incidence of side effects. ${ }^{4}$

We found that the onset and time for complete sensory block were significantly faster in the dexmedetomidine group (Group D) when compared to the clonidine group (Group C). Onset of motor block was also significantly early in Group D. Similar observations were noted in studies by Kavitha Jinjil et $\mathrm{al}^{5}$ and Don Sebastian et al. ${ }^{6}$ The total duration of sensory and motor block were also significantly longer in Group D in our study. Similar to observations by Swami SS et al,7 Marhofer D et al, ${ }^{8}$ Harshvardhan HS $^{9}$ and Zhang et al. ${ }^{10}$ However, dexmedetomidine was also associated with an increased incidence of side effects, such as bradycardia and hypotension.

Mechanisms proposed explaining the efficacy of dexmedetomidine in improving the quality and prolonging the duration of block are:

Vasoconstriction around the injection site. ${ }^{11-13}$

Direct suppression of impulse propagation through neurons by blocking voltage gated $\mathrm{K}+$ channels and thus causing membrane hyperpolarisation, thereby slowing or blockade of impulse conduction.14-15 
Local release of enkephalin like substances. ${ }^{16}$

Decrease in localised inflammatory mediators and increase in anti-inflammatory mediators. ${ }^{17}$

Inhibition of nerve action potential (AP) conduction and thus have an enhanced local anaesthetic effect. 18

Blockade of sodium channels by local anaesthetics with membrane hyperpolarisation and reduction of calcium influx inhibiting neurotransmitter release in the presynaptic Cfibres by $\alpha 2$ agonists result in earlier onset of sensory and motor block. The concentration-dependent, reversible blockade of compound action potentials in peripheral nerve fibres by $\alpha 2$ agonists is more on $\mathrm{C}$-fibres than $\mathrm{A} \delta$-fibres. Dexmedetomidine also produces analgesia at supraspinal level by acting on locus coeruleus; at spinal level by inhibiting neurotransmitters at substantia gelatinosa of dorsal horn and inhibiting release of substance $P$.

Sedation with dexmedetomidine, akin to natural sleep is due to its action on locus coeruleus. In fact it promotes REM sleep and is known to produce "conscious and cooperative sedation."

\section{CONCLUSION}

From our study, we conclude that dexmedetomidine when used as adjuvant to local anaesthetics in brachial plexus block as compared to clonidine has following beneficial effects-

1. Faster onset of sensory and motor block.

2. Longer duration of sensory and motor block.

3. Longer duration of analgesia.

\section{Limitations}

One of the limitations of this study was that we did not use ultrasound and nerve locator guided peripheral nerve block due to its non-availability in our setup. This could have helped us for accurate deposition of drugs around the plexus.

\section{REFERENCES}

[1] Hadzic A. Supraclavicular Brachial Plexus Block. Hadzic's peripheral nerve blocks and anatomy for ultrasound guided regional anaesthesia. $2^{\text {nd }}$ edn. New York, USA: McGraw Hill, 2012:167-74, 361-8.

[2] Elliott S, Eckersall S, Fliqelstone L, et al. Does the addition of clonidine affect duration of analgesia of bupivacaine wound infiltration in inguinal hernia surgery? Br J Anaesth 1997;79(4):446-9.

[3] Singelyn FJ, Gouverneur JM, Robert A. A minimum dose of clonidine added to mepivacaine prolongs the duration of anesthesia and analgesia after axillary brachial plexus block. Anesth Analg 1996;83(5):104650 .

[4] Zand F, Razavizadeh MR, Azemati S. Comparative study of onset and duration of action of $0.5 \%$ bupivacaine and a mixture of $0.5 \%$ bupivacaine and $2 \%$ lidocaine for epidural anesthesia. Acta Medica Iranica 2004;42(4):256-8.

[5] Jinjil K, Bhatnagar V, Swapna P, et al. Comparative evaluation of Alpha two agonists dexmedetomidine with clonidine as adjuvants to $0.25 \%$ ropivacaine for ultrasound guided supraclavicular block: a randomised double-blind prospective study.
International J of Healthcare and Biomedical Research 2015;3(3):20-31.

[6] Sebastian D, Ravi M, Dinesh K, et al. Comparison of dexmedetomidine and clonidine as adjuvant to ropivacaine in supraclavicular brachial plexus nerve blocks. IOSR Journal of Dental and Medical Sciences 2015;14(3):91-7.

[7] Swami SS, Keniya VM, Ladi SD, et al. Comparison of dexmedetomidine and clonidine ( $\alpha 2$ agonist drugs) as an adjuvant to local anaesthesia in supraclavicular brachial plexus block: a randomised double-blind prospective study. Indian J Anaesth 2012;56(3):243-9.

[8] Marhofer D, Kettner SC, Marhofer P, et al. Dexmedetomidine as an adjuvant to ropivacaine prolongs peripheral nerve block: a volunteer study. $\mathrm{Br}$ J Anaesth 2013;110(3):438-42.

[9] Harshavardhana HS. Efficacy of dexmedetomidine compared to clonidine added to ropivacaine in supraclavicular nerve blocks: a prospective, randomized, double blind study. Int J Med Health Sci 2014;3(2):127-32.

[10] Zhang Y, Wang CS, Shi JH, et al. Perineural administration of dexmedetomidine in combination with ropivacaine prolongs axillary brachial plexus block. Int J Clin Exp Med 2014;7(3):680-5.

[11] Ebert TJ, Hall JE, Barney JA, et al. The effects of increasing plasma concentrations of dexmedetomidine in humans. Anaesthesiology 2000;93(2):382-94.

[12] Yoshitomi T, Kohjitani A, Maeda S, et al. Dexmedetomidine enhances the local anaesthetic action of lidocaine via an alpha-2A adrenoceptor. Anesth Analg 2008;107(1):96-101.

[13] Saadawy I, Boker A, Elshahawy MA, et al. Effect of dexmedetomidine on the characteristics of bupivacaine in a caudal block in paediatrics. Acta Anaesthesiol Scand 2009;53(2):251-6.

[14] Butterworth JF, Strichartz GR. The $\alpha$ lpha 2-adrenergic agonists clonidine and guanfacine produce tonic and phasic block of conduction in rat sciatic nerve fibers. Anesth Analg 1993;76(2):295-301.

[15] Chen BS, Peng H, Wu SN. Dexmedetomidine, an $\alpha 2-$ adrenergic agonist, inhibits neuronal delayed-rectifier potassium current and sodium current. Br J Anaesth 2009;103(2):244-54.

[16] Nakamura M, Ferreira SH. Peripheral analgesic action of clonidine: mediation by release of endogenous enkephalin-like substances. Eur J Pharmacol 1988;146(2-3):223-8.

[17] Romero-Sandoval EA, McCall C, Eisenach JC. Alpha2adrenoceptor stimulation transforms immune responses in neuritis and blocks neuritis-induced pain. J Neurosci 2005;25(39):8988-94.

[18] Gaumann DM, Brunet PC, Jirounek P. Clonidine enhances the effects of lidocaine on C-fiber action potential. Anesth Analg 1992;74(5):719-25.

[19] Popping DM, Elia N, Marret E, et al. Clonidine as an adjuvant to local anaesthetic for peripheral nerve and plexus blocks: a meta-analysis of randomized trials. Anesthesiology 2009;111(2):406-15. 
[20] Virtanen R, Savola JM, Saano V, et al. Characterisation of selectivity, specificity and potency of medetomidine as an alpha 2-adrenoceptor agonist. Eur J Pharmacol 1988;150(1-2):9-14.
[21] Gandhi R, Shah A, Patel I. Use of dexmedetomidine along with bupivacaine for brachial plexus block. National Journal of Medical Research 2012;2(1):67-9. 